\title{
Polar mesosphere winter echoes during MaCWAVE
}

\author{
S. Kirkwood ${ }^{1}$, E. Belova ${ }^{1}$, U. Blum ${ }^{2, *}$, C. Croskey ${ }^{3}$, P. Dalin ${ }^{1}$, K.-H. Fricke ${ }^{2}$, R. A. Goldberg ${ }^{4}$, J. Manninen ${ }^{5}$, \\ J. D. Mitchell ${ }^{3}$, and F. Schmidlin ${ }^{6}$ \\ ${ }^{1}$ Swedish Institute of Space Physics, Box 812, 98128 Kiruna, Sweden \\ ${ }^{2}$ Physikalisches Institut der Universität Bonn, 53115 Bonn, Germany \\ ${ }^{3}$ EE Dept., Pennsylvania State University, University Park, PA 16802, USA \\ ${ }^{4}$ NASA/GSFC, Code 612.3, Greenbelt, MD20771, USA \\ ${ }^{5}$ Sodankylä Geophysical Observatory, Tähteläntie 62 FIN-99600 Sodankylä, Finland \\ ${ }^{6}$ Code 972, NASA/GSFC/Wallops Flight Facility, Wallops Is. VA 23337, USA \\ *now at: Forsvarets Forskningsinstitutt, N-2027 Kjeller, Norway
}

Received: 12 April 2005 - Revised: 7 November 2005 - Accepted: 21 December 2005 - Published: 3 July 2006

Part of Special Issue "MaCWAVE: a rocket-lidar-radar program to study the polar mesosphere during summer and winter"

\begin{abstract}
During the MaCWAVE winter campaign in January 2003, layers of enhanced echo power known as PMWE (Polar Mesosphere Winter Echoes) were detected by the ESRAD $52 \mathrm{MHz}$ radar on several occasions. The cause of these echoes is unclear and here we use observations by meteorological and sounding rockets and by lidar to test whether neutral turbulence or aerosol layers might be responsible. PMWE were detected within $30 \mathrm{~min}$ of meteorological rocket soundings (falling spheres) on 5 separate days. The observations from the meteorological rockets show that, in most cases, conditions likely to be associated with neutral atmospheric turbulence are not observed at the heights of the PMWE. Observations by instrumented sounding rockets confirm low levels of turbulence and indicate considerable small-scale structure in charge density profiles. Comparison of falling sphere and lidar data, on the other hand, show that any contribution of aerosol scatter to the lidar signal at PMWE heights is less than the detection threshold of about $10 \%$.
\end{abstract}

Keywords. Meteorology and atmospheric dynamics (Turbulence; Middle atmosphere dynamics) Ionosphere (Polar ionosphere)

\section{Introduction}

Polar mesosphere winter echoes (PMWE) are thin layers of strongly enhanced radar echo occasionally seen by high-latitude VHF radars such as the ESRAD $(52 \mathrm{MHz})$ and EISCAT $(224 \mathrm{MHz})$ radars in northern Scandinavia

Correspondence to: S. Kirkwood

(sheila.kirkwood@irf.se)
(Kirkwood et al., 2002a, 2002b; Stebel et al., 2004; Belova et al., 2005). It has long been known that layers of relatively weakly enhanced radar echo can be seen in the mesosphere at many latitudes, and strongly enhanced echoes are also known to occur at high-latitudes in summer. For example Ecklund and Balsley (1981) and Balsley et al. (1983), using the $50 \mathrm{MHz}$ Poker Flat radar, Alaska, and Czechowsky et al. (1989), using the mobile $53.5 \mathrm{MHz}$ SOUSY radar at Andenes, Norway, reported climatologies of radar echoes at high-latitudes. Strong echoes were seen in summertime at heights roughly $80-90 \mathrm{~km}$ (typically with signal-to-noise ratio, SNR, 30-60 dB at Andenes), and much weaker echoes were seen between 55-80 km heights in winter (SNR 5-25 dB at Andenes). It was realised early on that the strong summer echoes, later named PMSE - Polar Mesosphere Summer Echoes, could not be explained simply by the action of neutral turbulence and it was proposed that charged ice particles could play a role in their formation (Kelley et al., 1987). This theory has been largely substantiated by later studies (see e.g. reviews by Cho and Kelley, 1993, Cho and Röttger, 1997, Rapp and Lübken, 2004). The much weaker wintertime-high-latitude and lower-latitude echoes, on the other hand, were clearly correlated with dynamic processes (winds and wave motions) and it was considered that layers of neutral turbulence could provide an adequate explanation. Indeed, in-situ observations of small scale structure made by a sounding-rocket through a typical, weak mesospheric layer, seen by the $50 \mathrm{MHz}$ Jicamarca radar in Peru (Røyrvik and Smith, 1984), were found to be in good quantitative agreement with a turbulent production mechanism (radar volume reflectivity was $2 \times 10^{-18} \mathrm{~m}^{-1}$, turbulent energy dissipation rate $50 \mathrm{~mW} / \mathrm{kg}$ ).

Published by Copernicus GmbH on behalf of the European Geosciences Union. 

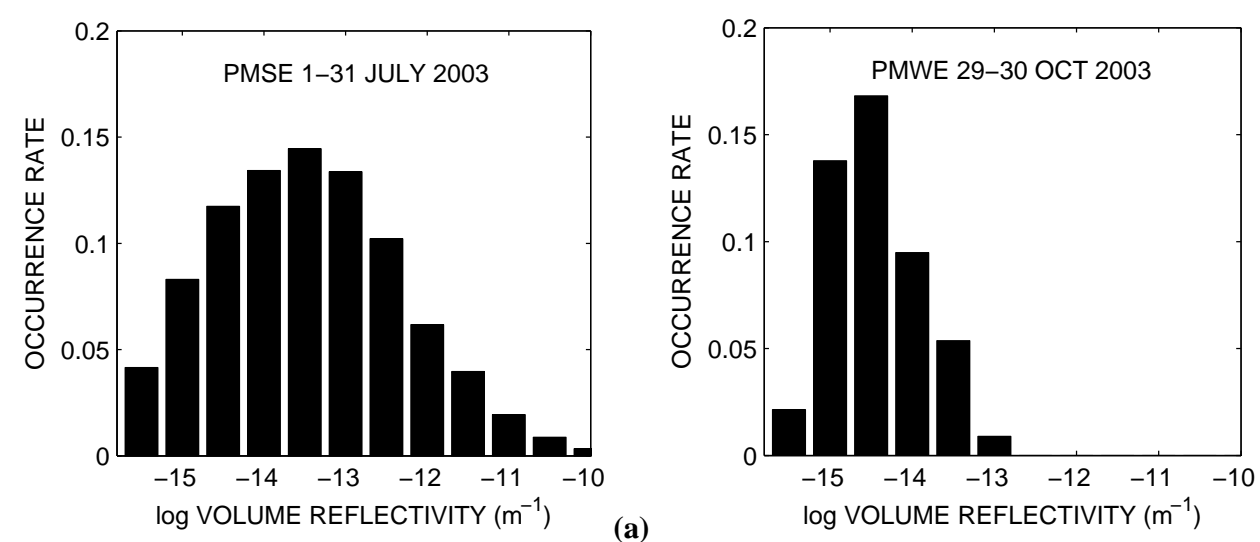

(a)

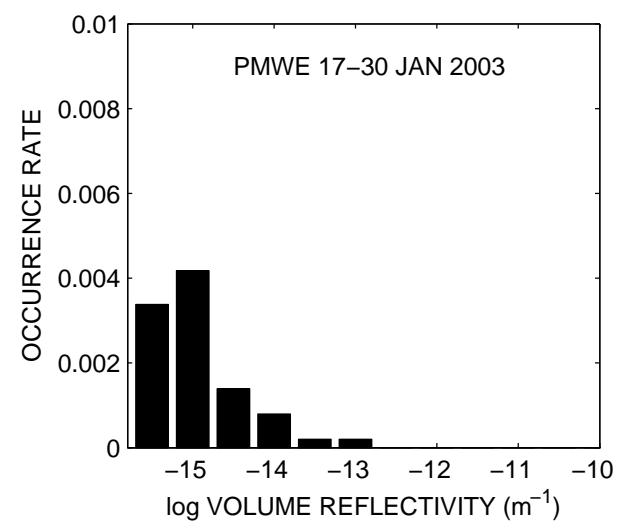

(c)

Fig. 1. Statistical analysis of the maximum volume reflectivity associated with radar echoes from the mesosphere observed by the ESRAD $52 \mathrm{MHz}$ radar during different conditions. Maximum volume reflectivity is the maximum observed in each 2-min averaged height profile between the heights specified below. Occurrence rate is the fraction of total time when profiles with maximum volume reflectivity in the relevant interval were observed. Top panel shows the results for summer, heights $80-90 \mathrm{~km}$, for the whole of July 2003 . Middle panel shows the results for winter, heights 50-75 km, during a major solar proton event in October 2003 (Belova et al., 2005). Lowest panel shows the results for winter, heights 50-75 km, during the MacWAVE campaign in January 2003. All measurements were made with the same radar operating parameters. The derivation of volume reflectivity is as described in Stebel et al. (2004).

The ESRAD $52 \mathrm{MHz}$ radar is 2-4 orders of magnitude less sensitive than the Poker Flat, Andenes and Jicamarca radars mentioned above. Although it regularly observes mesospheric echoes in the summer, it was not expected to be able to detect the much weaker wintertime echoes. The observation of wintertime echoes with strengths comparable to the summertime echoes was unexpected. These echoes were first reported by Kirkwood et al. (2002a), and named Polar Mesosphere Winter Echoes, PMWE. The relationship between PMWE and PMSE is illustrated by Fig. 1, which shows typical strengths of summertime PMSE (uppermost panel) and compares with typical PMWE as previously reported in association with solar proton events (middle panel, see also Belova et al., 2005). The lowermost panel shows a comparison with PMWE observed without a concurrent solar proton event, which are the subject of this paper. Volume reflectivities have been estimated using the method described in Stebel et al. (2004). The ESRAD radar, in the configuration used for these measurements, cannot reliably detect echoes with volume reflectivity less than $3 \times 10^{-16} \mathrm{~m}^{-1}$. It should be noted that the PMWE in the lower two panels are 2-5 orders of magnitude stronger than the turbulence-produced echo described by Røyrvik and Smith, 1984. They are also comparable in strength to the lowest part of the PMSE distribution shown in the uppermost panel. They are therefore much stronger also than the high-latitude wintertime echoes reported earlier which, according to Czechowsky et al. (1989), were typically 2-3 orders of magnitude weaker than PMSE.

The appearance of PMWE during solar proton events has previously been reported and it has been argued that they are much too strong to be explained by layers of neutral turbulence and that they may be evidence for charged aerosol layers in the winter mesosphere (Kirkwood et al., 2002a, 2002b; Stebel et al., 2004; Belova et al., 2005). During 

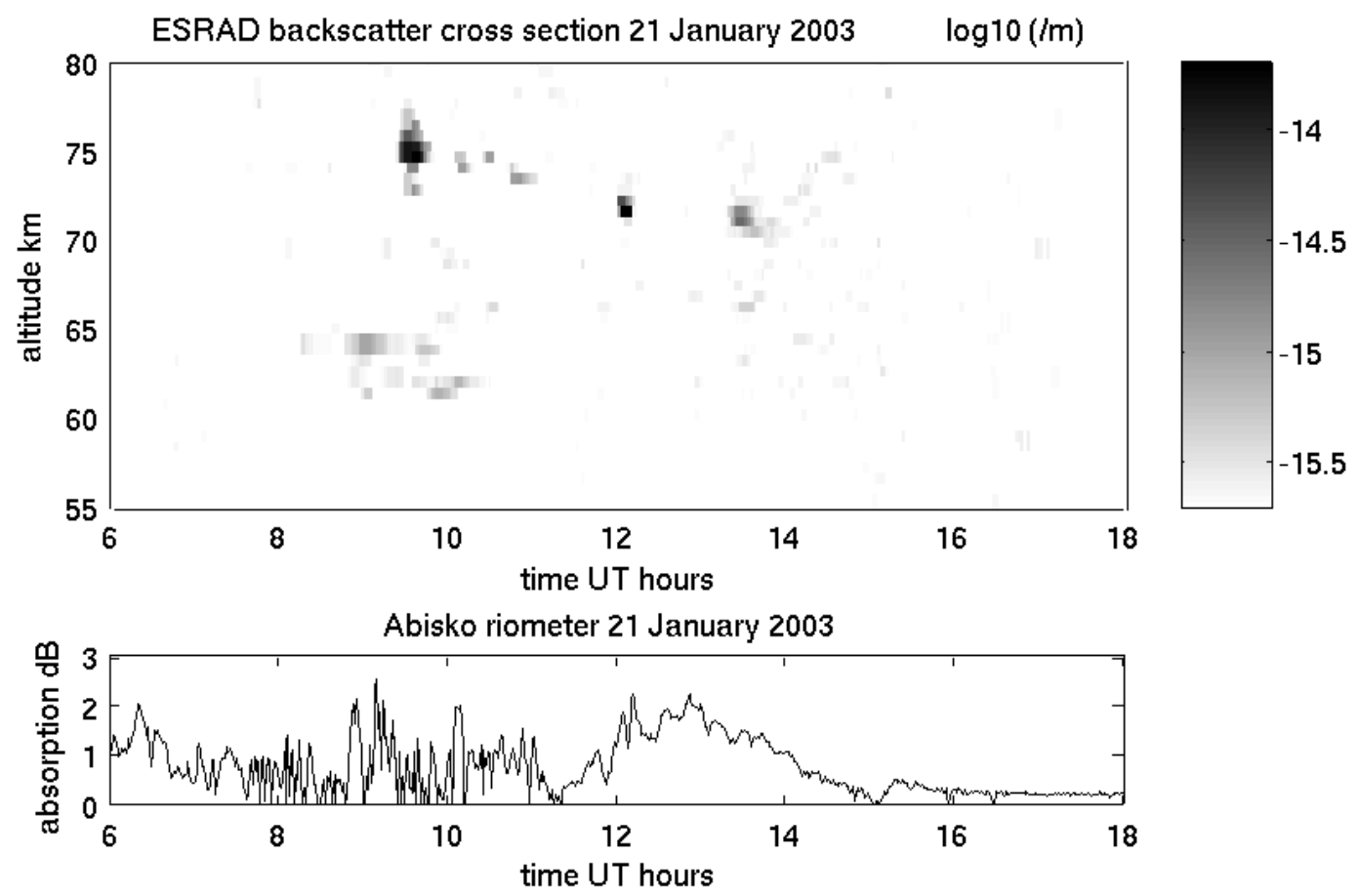

Fig. 2. Upper Panel: typical PMWE measured by the ESRAD $52 \mathrm{MHz}$ radar during the MaCWAVE campaign. This example shows radar observations 06:00-18:00 UT on 21 January 2003, with distinct echo layers visible between $\sim 08$ UT and $\sim 16$ UT. Lower panel: simultaneous cosmic noise absorption measured by the $30 \mathrm{MHz}$ riometer in Abisko, showing a signature typical of morning-side precipitation of high energy particles from the magnetosphere.

the MaCWAVE winter campaign at Esrange (15 January1 February 2003) PMWE were detected by the ESRAD radar on 10 of the 18 campaign days. PMWE echo strengths are summarised in the lowest panel of Fig. 1, and a typical example is shown in Fig. 2. There were no solar proton events during the campaign period and the extra ionization needed to make mesospheric layers "visible" to the radar was probably provided by high-energy electron precipitation from within the magnetosphere. This is evidenced by riometer data which show daytime absorption events of the type usually associated with the latter type of precipitation (see e.g. Kirkwood and Osepian, 2001b).

As outlined above, the "traditional" explanation for layers of enhanced radar echo in the high-latitude winter mesosphere is strong turbulence due to wave-breaking or windshear (Balsley et al., 1983; Czechowsky et al., 1989). The need to propose that charged aerosol are involved in the scatter is a consequence of the strong echo power associated with PMWE and the relatively weak levels of turbulence which have in practice been detected by sounding-rocket instruments in the high-latitude winter mesosphere during earlier campaigns from Andøya, in Arctic Norway (Lübken et al., 1993; Lübken, 1997). Such turbulence levels are insufficient to generate significant fluctuations in the radar refractive index at the scale-sizes represented by the ESRAD and EISCAT radars $(3 \mathrm{~m}$ and $70 \mathrm{~cm}$, respectively) unless charged aerosols are present (Stebel et al., 2004). In a comparison of PMWE with lidar measurements, Stebel et al. (2004), reported an approximately $10 \%$ increase of lidar backscatter at PMWE heights, consistent with the presence of an aerosol layer. However it was not possible to completely rule out the possibility that the anomalous lidar profile was due to a temperature wave, rather than an aerosol layer, since no independent measurements of atmospheric density or temperature were available.

The most comprehensive measurements of background atmospheric conditions during PMWE reported so far were during a solar proton event in November 2003, when both the ESRAD and EISCAT radars observed PMWE over a period of several hours (Belova et al., 2005). In addition to direct observations of PMWE, the EISCAT data also provided information on background electron density profiles and on meridional wind profiles and on gravity-wave periods. The latter gave the possibility to estimate wind shears and to find a lower limit for the buoyancy period. The conclusion was, once more, that turbulence levels should be much too low to explain the strength of the PMWE echoes, provided the wind-shear - turbulence relation found by Lübken at al. (1993), is applicable, and assuming that the background electron density profiles measured by EISCAT are representative of conditions within the PMWE layer. However, complete information on wind shears and buoyancy period were 


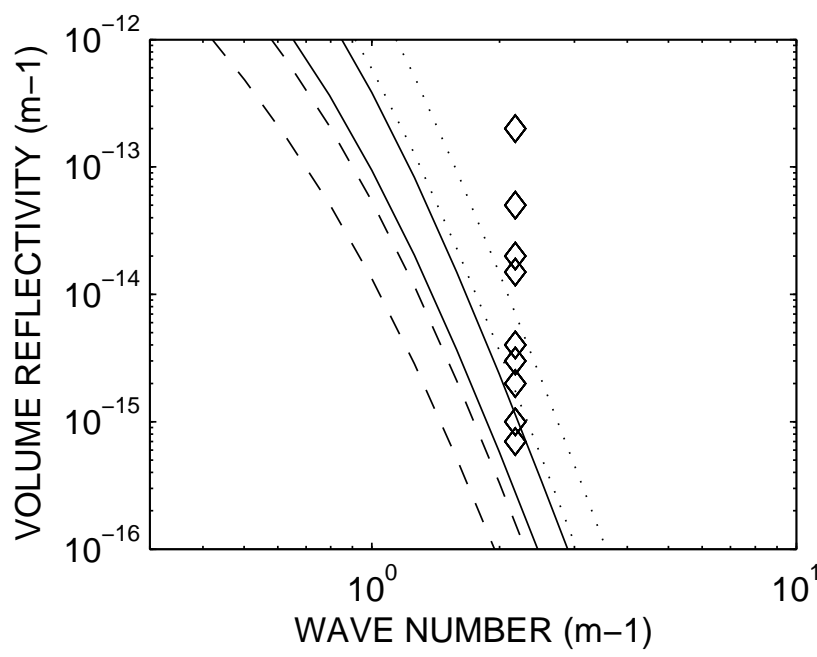

Fig. 3. PMWE volume reflectivities estimated using ESRAD $(<>)$ during the MaCWAVE campaign (see text and Table 1 for details) compared with theoretical calculations for reflectivity due to neutral turbulence. The calculations are for $70 \mathrm{~km}$ altitude (viscosity $0.25 \mathrm{~m}^{2} \mathrm{~s}^{-1}$ ), electron densities $1.5,4$ and $10 \times 10^{9} \mathrm{~m}^{-3}$ (dotted, solid and dashed lines, respectively), electron density (1/e) scale height $4.3 \mathrm{~km}$, and $\mathrm{N}^{2}=2 \times 10^{-4} \mathrm{~s}^{-2}$ or $6 \times 10^{-4} \mathrm{~s}^{-2}(\mathrm{~N}=$ BruntVaisala frequency), turbulent energy dissipation rate $100 \mathrm{~mW} / \mathrm{m}^{3}$.

not available so that further tests are still needed.

In this study we make detailed comparison of PMWE profiles with the likelihood of strong turbulence generation - using information on static stability (buoyancy period) and wind shear from falling spheres released from meteorological rockets during the MaCWAVE campaign. We further compare lidar backscatter profiles (averaged over several hours) with falling-sphere density profiles (also averaged over several flights) to determine whether observed "anomalies" in the lidar profiles are more likely to be due to aerosol layers or to waves in the temperature profile.

\section{ESRAD radar observations}

The ESRAD $52 \mathrm{MHz}$ atmospheric radar is located at the Esrange launch site $\left(67^{\circ} 53^{\prime} \mathrm{N}, 21^{\circ} 06^{\prime} \mathrm{E}\right)$. The measurements shown here were made using 8-bit complementary codes with $600 \mathrm{~m}$ altitude resolution. One profile $(4.8 \mathrm{~km}-100 \mathrm{~km}$ altitude) was measured every second minute. The reflected signal power can be calibrated by comparison with the daily variation of the cosmic radio noise. Using absolute measurements of the cosmic noise at $45 \mathrm{MHz}$ (Maeda et al., 1999) and the known characteristics of the radar (antenna aperture, transmitter power, receiver bandwidth) it is possible to estimate the volume reflectivity in the PMWE in absolute units, suitable for comparison with theoretical predictions of radar-echo power due to turbulence (for details see Stebel et al., 2004). The uncertainty associated with the compar- ison between the signal strength and the daily variation of the cosmic noise is about $\pm 20 \%$. PMWE volume reflectivities estimated in this way, during the MaCWAVE campaign, are shown in Figs. 1 and 3 and are listed in Table 1. Note that three assumptions have had to be made - the first that the scattering volume is filled by turbulence, the second that there are no significant losses in the radar antenna, and the third that the transmitter is operating at its full nominal power. These assumptions imply that the plotted and tabulated volume reflectivities from ESRAD are likely to be underestimates of the true volume reflectivity of PMWE. The underestimate due to non-optimal performance of the radar hardware is not likely to exceed a factor 2 whereas the potential underestimate due to scattering structures being much narrower that the nominal range-gate can in principle be up to 2 orders of magnitude.

In Fig. 3, the estimated PMWE volume reflectivities are compared with predicted reflectivities for echoes due to neutral turbulence. The method of calculation is described in detail in Stebel et al. (2004). We have assumed neutral atmosphere density and viscosity corresponding to $70 \mathrm{~km}$ altitude, and a turbulent energy dissipation rate of $100 \mathrm{~mW} / \mathrm{kg}$, which is rather more than the highest disspiation rates found in turbulent layers in the high-latitude winter mesosphere reported from earlier sounding-rocket measurements (Lübken et al., 1993; Lübken, 1997). Turbulent energy dissipation rates were also estimated using Langmuir probes on instrumented sounding rockets launched at Esrange during the MacWAVE campaign at 20:50 UT on 24 January and 18:32 UT on 28 January. No evidence was found for turbulence exceeding $1 \mathrm{~mW} / \mathrm{kg}$ at heights below $75 \mathrm{~km}$, although values up to $200 \mathrm{~mW} / \mathrm{kg}$ were found in the height range $83-86 \mathrm{~km}$ in the latter flight.

No direct measurements of electron density profile are available for the times of the PMWE observations in Table 1. That electron densities were enhanced above quiet levels is clearly demonstrated by riometer records from the several riometers covering the location of the radar (http: //www.sgo.fi/Data/archive.php). It is also apparent from the publically available data from the GOES satellites (http: //www.sel.noaa.gov/today.html) that there were neither significant fluxes of solar protons nor any large solar X-ray flares to cause enhanced ionisation. The characteristics of the ionisation variations show by the riometers are typical for morningside high-energy electron precipitation from within the magnetosphere. Such events have been studied both theoretically and experimentally (see, e.g. Kennel and Petsheck, 1966; Lyons et al., 1971, 1972; Lyons and Williams 1984; Kirkwood and Osepian, 2001a, 2001b) and it is well established that the ionisation at mesospheric altitudes comes from electrons from the high-energy tail of the trapped particle population in the magnetosphere, with fluxes controlled by time-varying pitch-angle scattering into the loss cone. It is also clear from both experimental data and theoretical considerations that the shape of the flux-energy spectrum of 
Table 1. Observations of PMWE using ESRAD, cosmic noise absorption from the Abisko riometer (30 MHz) and squared buoyancy frequency $\left(N^{2}\right)$ and Richardson number from MaCWAVE falling-spheres during January 2003.

* indicate occasions when there was no PMWE visible exactly at the time of the rocket flight - comparison is then made with PMWE seen $1-2 \mathrm{~h}$ earlier.

\begin{tabular}{|c|c|c|c|c|c|c|c|c|}
\hline date & $\begin{array}{l}\text { PMWE } \\
\text { time } \\
\text { UT }\end{array}$ & $\begin{array}{l}\text { PMWE } \\
\text { minimum } \\
\text { solar elev. } \\
\text { degrees }\end{array}$ & $\begin{array}{l}\text { PMWE } \\
\text { height } \\
\text { km }\end{array}$ & $\begin{array}{l}\text { PMWE } \\
\text { backscatter } \\
\mathrm{m}^{-1}\end{array}$ & $\begin{array}{l}\text { RIOMETE } \\
\text { R } \\
\text { 8-14 UT } \\
\text { max abs. } \\
\text { dB }\end{array}$ & $\begin{array}{l}\text { SPHERE } \\
\text { time } \\
\text { UT }\end{array}$ & $\begin{array}{l}\text { SPHERE } \\
N^{2} \quad \text { (at PMWE } \\
\text { height )* } \\
\mathrm{s}^{-2}\end{array}$ & $\begin{array}{l}\text { SPHERE } \\
\text { Richardson } \\
\text { number } \\
\text { (at PMWE } \\
\text { height )* }\end{array}$ \\
\hline 17 Jan & $11-14$ & -8 & $64-70$ & $30 \times 10^{-16}$ & 1.0 & 13 & $3-5 \times 10^{-4}$ & $2-4$ \\
\hline 19 Jan & $10-11$ & -3 & $62-68$ & $7 \times 10^{-16}$ & 2.0 & 13 & $\left(0-4 \times 10^{-4}\right)^{*}$ & $(0.1-1)^{*}$ \\
\hline 21 Jan & $09-14$ & -6 & $61-76$ & $2000 \times 10^{-16}$ & 3.0 & 13 & $3-4 \times 10^{-4}$ & $3-4$ \\
\hline 22 Jan & $09-12$ & -6 & $64-75$ & $40 \times 10^{-16}$ & 1.0 & 13 & $\left(5 \times 10^{-4}\right)^{*}$ & $(1-4)^{*}$ \\
\hline 25 Jan & $10-12$ & -4 & $65-73$ & $200 \times 10^{-16}$ & 4.0 & 01 & & \\
\hline 26 Jan & $11-14$ & -8 & $65-76$ & $20 \times 10^{-16}$ & 2.5 & 13 & $2-4 \times 10^{-4}$ & 4 \\
\hline 27 Jan & $13-14$ & -4 & $73-74$ & $10 \times 10^{-16}$ & 0.5 & 13 & $5 \times 10^{-4}$ & $16-20$ \\
\hline 28 Jan & $09-11$ & -10 & $68-77$ & $500 \times 10^{-16}$ & 1.5 & 13 & $\left(4-6 \times 10^{-4}\right)^{*}$ & $(4-100) *$ \\
\hline 30 Jan & $13-14$ & -6 & $68-77$ & $15 \times 10^{-16}$ & 1.5 & 13 & $5 \times 10^{-4}$ & $1-2$ \\
\hline
\end{tabular}

incoming electrons, and hence the shape of the resultant electron density profile, varies very little while the flux levels (and absolute electron densities) vary widely. Large numbers of electron-density observations have been made during these kinds of events both by incoherent-scatter radar and by sounding rockets and a statistical analysis is available in Friedrich et al. (2004). The absorption values measured by riometer are in principle sensitive to both absolute electron density and to the shape of the electron density profile. However, in the case of this type of event, the profile shape varies little and the absorption measured by riometer defines the whole profile, both the absolute electron density and the gradient at the altitude of interest for our PMWE comparison. Since we want to test whether turbulence alone, acting on an electron density profile due to particle precipitation, might explain our radar echoes, we do not at this stage consider whether fine structure might have been introduced into the electron density profile by other processes.

We have used electron densities and electron density gradients from Friedrich et al. (2004) corresponding to the range of absorption values observed by riometer at the times PMWE were seen. The dotted, solid, and dashed lines in Fig. 3 represent moderate, high and extremely high disturbance levels. For the different disturbance levels we use the 1,3 and $10 \mathrm{~dB}$ levels in $30 \mathrm{MHz}$ cosmic-noise absorption for the appropriate conditions (daytime, solar zenith $80^{\circ}$ ) from Friedrich et al. (2004). The corresponding electron densities at $70 \mathrm{~km}$ altitude are $1.5,4$ and $10 \times 10^{9} \mathrm{~m}^{-3}$, respec- tively. Note that the disturbance level in practice during our strongest PMWE events (on 21 January, see Fig. 2) does not exceed $2.5 \mathrm{~dB}$ (Table 1), so the $10 \mathrm{~dB}$ level represents 4 times higher electrons densities than are likely to have been present. The electron density gradient is also an important factor in the calculation of volume reflectivity. The observations analysed by Friedrich et al. (2004) generally suggest that the electron density gradient becomes rather flat at $70 \mathrm{~km}$, but those observations were made close to the lower limit (in height) of the observational techniques used. So we take instead the gradient just above $70 \mathrm{~km}$, where electron densities increase by a factor 10 as the height increases by $10 \mathrm{~km}$. This should be seen as an upper limit to the gradient so that calculated radar reflectivities will also be at the upper limit. We further calculate volume reflectivities for two different values of atmospheric stability, $N^{2}=2 \times 10^{-4} \mathrm{~s}^{-2}$ and $N^{2}=6 \times 10^{-4} \mathrm{~s}^{-2}$ ( $N=$ Brunt-Vaisala frequency $)$, representing the range of conditions we find in the mesosphere during the PMWE (see Table 1). The calculations are for sunlit conditions, when the proportion of negative ions is very small.

It can be seen that the weaker PMWE might, conceivably, be explained by turbulence while the stronger PMWE are an order of magnitude stronger than the theoretical values, even though we have used higher electron density and steeper electron density gradients than are likely for the theoretical calculation and the experimental PMWE volume reflectivities are likely underestimated. The same kind of discrepancy between measured and predicted (from turbulence) 
echo power is well known in the case of Polar Mesosphere Summer Echoes (PMSE) and it is there considered likely that the cause is the presence of layers of charged aerosol (Kelley, 1987; Cho and Kelley, 1993; Cho and Röttger, 1997; Rapp and Lübken, 2004). It is not surprising to find evidence for aerosol in the summer mesosphere where temperatures fall so low that water condenses. This can cause not only the fine aerosol needed to explain PMSE but also layers of large ice particles seen as visible clouds (noctilucent clouds). It is not expected that there should be significant amounts of aerosol in the winter mesosphere, however, since temperatures are well above those needed for water saturation. It is also possible that turbulence might be substantially stronger than reported by Lübken et al. (1993) and Lübken (1997), or fine-scale gradients might be introduced into the electron density profile by some unknown process, or the theoretical basis used for estimating the radar reflectivity due to turbulence (Hocking, 1985) might be inadequate. So it is important to perform further tests as to whether turbulence can definitively be ruled out as an explanation of PMWE. If, for example, much stronger turbulence than previously observed were present, it might possibly account for PMWE. The occurrence of PMWE during falling-sphere flights at the same location gives us the possibility to check if the atmospheric conditions were appropriate to generate and/or support turbulence, at least as far as winds and temperature gradients are concerned on the scales of a kilometer or more, as measured by the falling spheres.

\section{Falling-sphere measurements}

Falling spheres are used to measure winds, neutral densities and temperatures in the middle atmosphere. An inflated sphere is released from a small rocket at about $110 \mathrm{~km}$ altitude and tracked by radar as it falls. The fall speed depends on the deceleration due to the friction of the neutral atmosphere so that monitoring the fall speed gives a profile of atmospheric density. This can be integrated to derive a temperature profile. Horizontal winds can be derived from the horizontal movement of the sphere. For more details see, e.g. Schmidlin et al. (1991). The height resolution is of the order a kilometre or more, i.e. comparable to, but slightly longer than, the height resolution of the radar measurements which is $600 \mathrm{~m}$. It has previously been shown (Belova et al., 2005) that, when a continuous source of enhanced ionisation is available, layers of PMWE descend slowly following the phase descent of atmospheric waves with vertical wavelengths of several kilometres. It might then be that the temperature gradients and wind shears associated with such waves are a source of turbulence.

Falling sphere results for the 5 flights when PMWE were seen within 30 min of the sphere launch, are shown in Fig. 4. The two left-hand panels show wind and temperature profiles from the standard falling-sphere analysis. The centre panels show wind shear (dashed line) and $N^{2}$ (solid line). Wind shear is calculated as $(\mathrm{d} u / \mathrm{d} z)^{2}+(\mathrm{d} v / \mathrm{d} z)^{2}$, where $u$ and $v$ are the zonal and meridional wind components, respectively, and $z$ is the vertical coordinate. Wind shear is a measure of the energy available to drive turbulence. Brunt-Vaisala frequency $N$ is a measure of atmospheric static stability - for $N^{2}<0$, the atmosphere is convectively unstable. In Fig. 3 we see that the static stability $N^{2}$ is highest above ca $66 \mathrm{~km}$. At lower heights $N^{2}$ is smaller, and on 17, 21 and 27 January, even falls below zero in limited height regions between $63 \mathrm{~km}$ and $66 \mathrm{~km}$.

The fourth panels in Fig. 4 show the Richardson number, $R i$, which is the ratio $N^{2} /\left[(\mathrm{d} u / \mathrm{d} z)^{2}+(\mathrm{d} v / \mathrm{d} z)^{2}\right]$. The final, right-hand panel in Fig. 4 shows the ESRAD observations of PMWE for the time period from $30 \mathrm{~min}$ before the time of the falling sphere measurements, up to the time of launch, and between $10-30 \mathrm{~min}$ after launch. The period $0-10 \mathrm{~min}$ after launch is excluded to avoid possible radar echoes from the rocket or from the sphere. Narrow spikes which do not reach the $0 \mathrm{~dB}$ level may simply be noise - PMWE are represented by the distinct layers which exceed this level.

Richardson number is the parameter commonly used to assess the chance that turbulence will be initiated (if $R i<0.25$ ) or that it can be supported (if $R i<1$ ), although these criteria really apply only to highly idealized flow conditions (Miles, 1961; Howard, 1961). It is clear that the Richardson number exceeds 0.25 everywhere, and 1 almost everywhere, except in the convectively unstable region where $N^{2}<0$ on 17,21 and 27 January. So, on the basis of this simplified criterium, it seems that the $\mathrm{km}$-scale dynamic features cannot be expected to support turbulence, except in the latter unstable regions. A more rigorous analysis of the atmospheric conditions associated with turbulence is provided by the direct numerical simulation results reported by Fritts et al. (2003). In the latter paper, turbulent layers generated by shear (Kelvin-Helmholtz) instability and by breaking gravity waves are considered, for conditions representative of the upper mesosphere. In the case of shear instability, Fritts et al. found that a layer of turbulence was formed, with about 3 times the depth of the initial flow-shear. Richardson number varied between 0.25 and 1 in the turbulent layer (with the lowest values in the middle of the layer) and the fluctuations most likely to lead to radar echoes were strongest close to the upper and lower edges of the layer. If PMWE were associated with the edges of such turbulent layers, and the thickness of the layers was a few $\mathrm{km}$ or more, and so resolved by the falling spheres, we would expect PMWE to be seen just above or just below zones where $R i$ falls to 0.25 or below. There is only one case in Fig. 4 where this occurs - at about $65 \mathrm{~km}$ on 21 January. The possibility remains that turbulent zones are less than $1 \mathrm{~km}$ thick, as, in several cases, PMWE are seen in only $1-3$ of the radars range gates, which are nominally $600 \mathrm{~m}$ thick, but in practice extend over $1200 \mathrm{~m}$ with a $50 \%$ overlap between adjacent gates. The falling sphere technique would then not be able resolve the associated fall in $R i$ for layers 

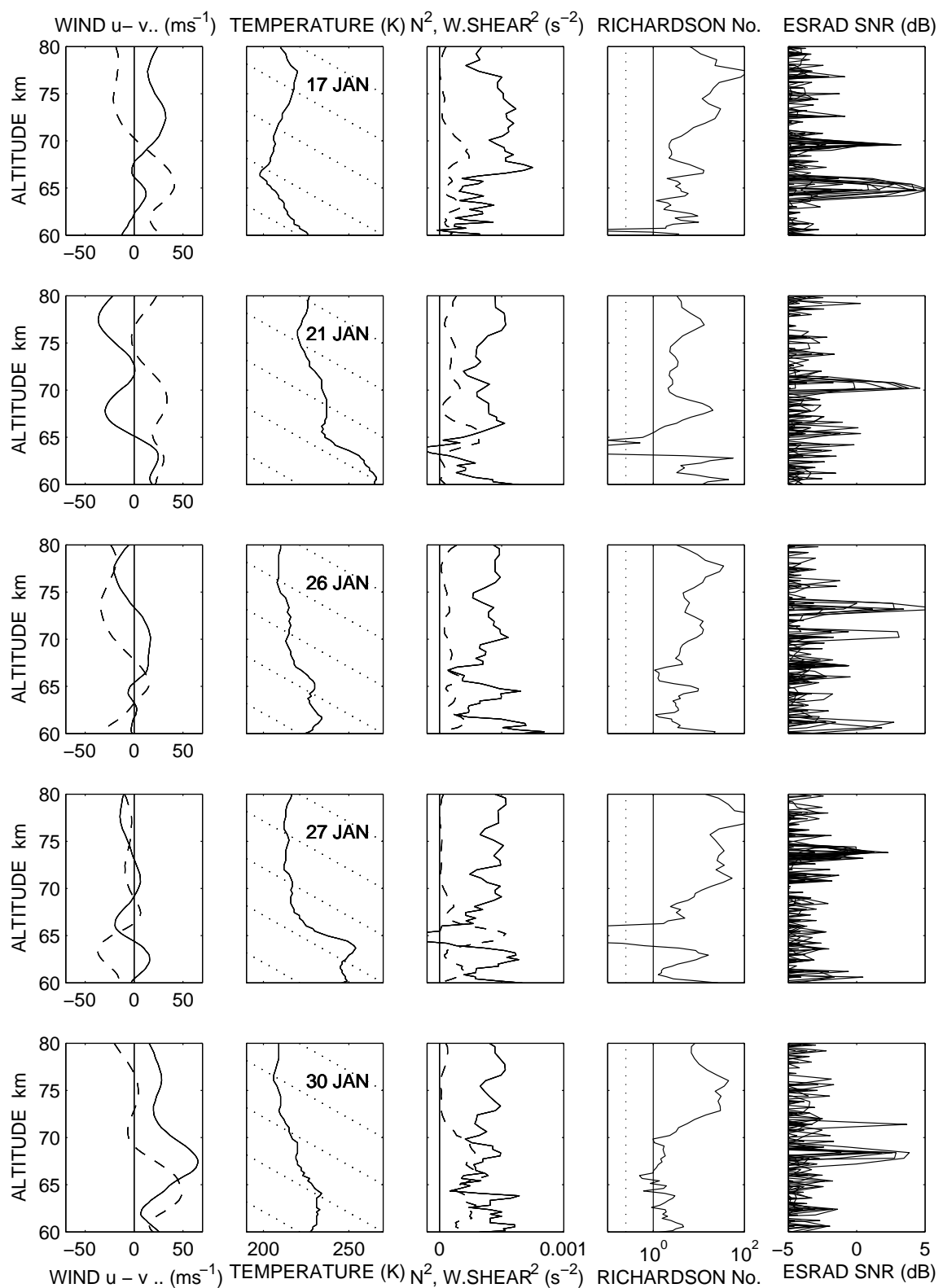

Fig. 4. Comparison of falling-sphere measurements (leftmost 4 panels in each row) and ESRAD observations of PMWE (rightmost panel in each row) on 17, 21, 26, 27 and 30 January. Leftmost panels show wind components (solid line: u, eastward wind, dashed line: v, northward wind) and temperature measured by the falling spheres (dotted lines indicate the adiabatic lapse rate, for comparison). The centre panels show the square of the wind-shear (dashed line), the square of the Brunt-Vaisala frequency, $N^{2}$ ( solid line), and the Richardson number, which is the ratio of the former two quantities. These parameters are derived from the falling-sphere measurements. Vertical lines on the panels showing Richardson number mark $R i=0.25$ (dotted) and $R i=1$ (solid). The right-hand panels show the ESRAD observations of PMWE for the time period from $30 \mathrm{~min}$ before the time of the falling sphere measurements, up to the time of launch, and between 10-30 min after launch. The period $0-10 \mathrm{~min}$ after launch is excluded to avoid possible radar echoes from the rocket or from the sphere.

less than $1-2 \mathrm{~km}$ thick. There is however one case, at about $65 \mathrm{~km}$ altitude on 17 January where the PMWE layers is at least $2 \mathrm{~km}$ thick and low values of $R i$ should have been detected by the falling sphere, if they were present.

Fritts et al. (2003) also considered the turbulence produced by breaking gravity waves. This cannot provide an explana- tion for PMWE of the type seen during solar proton events (e.g. Belova et al., 2005) since they are seen continuously while turbulence due to breaking gravity waves should be intermittent. However, in the present case, PMWE are intermittent and although this may well be due to intermittent ionisation, we cannot rule out the possibility that it is due 

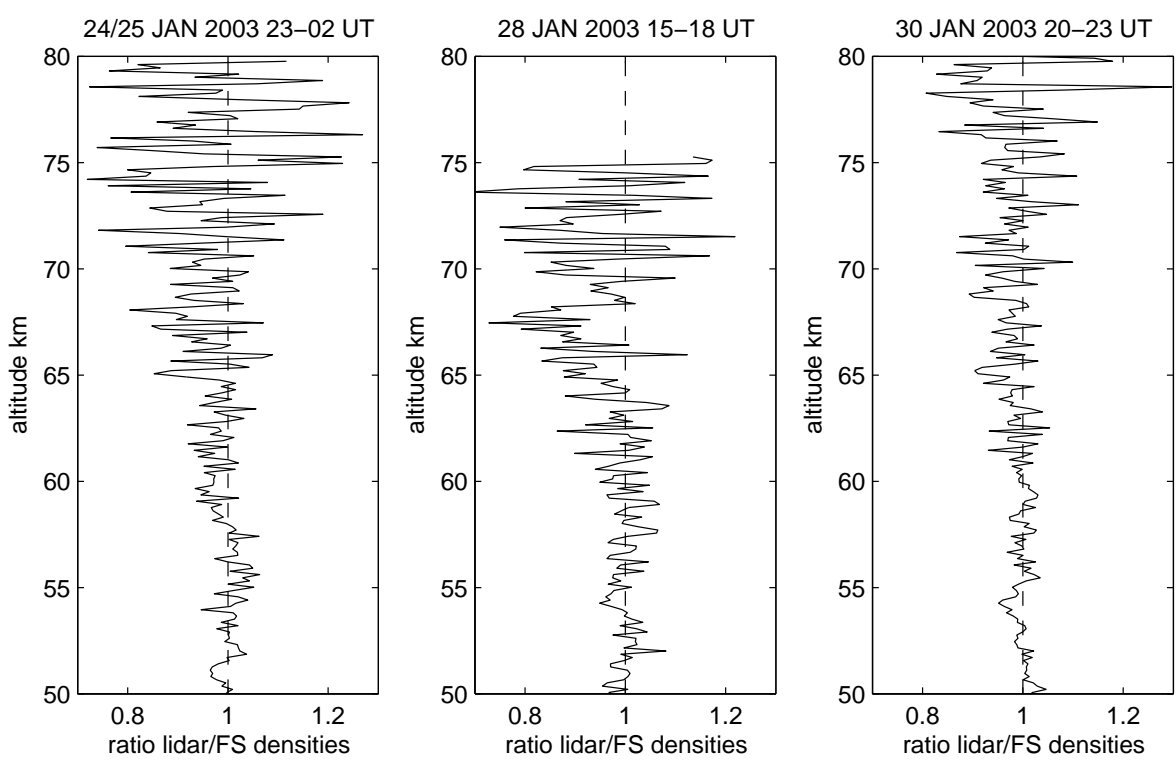

Fig. 5. Ratio of atmospheric backscatter from lidar and neutral number densities from falling sphere measurements on 3 occasions. In each case lidar measurements are integrated over $2-3 \mathrm{~h}$, and measurements from several falling spheres are averaged. The ratio is normalised so that the average over the height interval $50-60 \mathrm{~km}$ is 1 . For 24/25 January, lidar integration time is 23:31-01:27 UT, and spheres launched at 23:00, 00:00 and 00:58 UT are averaged. For 28 January, lidar integration time is 15:22-17:28 UT, and spheres at 15:04, 15:57, 17:05 and 17:57 UT are averaged. For 30 January, lidar integration time is 20:43-22:29 UT, and spheres at 21:10 and 22:03 UT are averaged.

to intermittent turbulence. According to Fritts et al. (2003), turbulence covering a depth of about half the vertical wavelength of the gravity wave is generated when the gravity wave amplitude grows to a level where the temperature gradient becomes adiabatic in the appropriate phase of the wave. The fluctuations likely to lead to radar scatter may be concentrated to the lower part of the adiabatic region, or spread more broadly. Once again, this description does not fit well with our observed PMWE, except perhaps in the case of the weak PMWE at $65 \mathrm{~km}$ on 21 January. However, once again we cannot rule out the possibility of effects due to gravity waves with wavelengths less than about $2 \mathrm{~km}$ in the case of narrow PMWE layers.

The results of the sphere-PMWE comparison can be summarised as follows:

(a) The falling sphere profiles show convectively unstable regions (Brunt-Vaisala frequency $<0$ ) at about 61, 64 and $65 \mathrm{~km}$ altitudes on 17, 21 and 27 January, respectively. PMWE (above the level of reliable detection, $\sim 0 \mathrm{~dB}$ SNR) do not appear in any of these regions, although a possible weak PMWE appears at the top of the unstable region on 21 January.

(b) The falling sphere profiles show dynamically unstable regions (Brunt-Vaisala frequency $>0$ but Richardson number $<1$ ) close to 62 and $66 \mathrm{~km}$ altitudes on $26 \mathrm{Jan}$ uary and close to 65 and $70 \mathrm{~km}$ altitudes on 30 January. PMWE appear close to the lower unstable height on 26 January and between the two unstable heights on 30 January.

(c) A total of 7 PMWE layers appeared at heights where the atmosphere was neither convectively nor dynamically unstable on the scale sizes resolved by the falling spheres (Brunt-Vaisala frequency $1.4-2.2 \times 10^{-2} \mathrm{~s}^{-1}$, Richardson numbers 2-4).

In conclusion, a majority of PMWE appeared at heights and times where the $\mathrm{km}$-scale profiles of background temperature and windshear are not those expected to be associated with neutral turbulence. Regions with adiabatic temperature gradients, which would be expected to be associated with turbulence, were seen at other heights and times. In all but one case, however, the PMWE are confined to narrow zones less than $1.2 \mathrm{~km}$ thick, so the possibility remains that they might be due to adiabatic temperature gradients or unstable windshear on scales which cannot be resolved by the falling spheres.

\section{Lidar observations}

The University of Bonn Rayleigh-Mie-Raman backscatter lidar, based on a frequency doubled Nd:YAG laser (Blum and Fricke, 2005) is situated about $2 \mathrm{~km}$ away from ESRAD. During January 2003 data were recorded with a height resolution of $150 \mathrm{~m}$. The lidar measures the intensity of light scattered from atmospheric molecules and from any aerosol 
which might be present. In the height region of interest here, the Raman scatter is too weak to be detected so is not possible to separate the aerosol and molecular contributions a priori. The usual assumption for the winter mesosphere is that there is no significant scatter from aerosol. One way to test this assumption is to compare backscatter profiles from the lidar with neutral density profiles derived from the falling sphere measurements. If the contribution of aerosol particle layers to the scatter is negligible, this ratio will be constant over height. Several hours of integration are required to reduce the stochastic noise so that the best comparisons can be made when a series of meteorological rockets were launched. This happened on 3 occasions, on the evenings of 24, 28 and 30 January. On each occasion, PMWE were seen earlier in the day between 68 and $75 \mathrm{~km}$ altitudes, but they were no longer detectable by the radar at the time the lidar measurements started. However, if PMWE are due to aerosol particle layers, it can be expected that they can be detected by radar only during daylight because of the dependence of aerosol charging on daylight (see, e.g. Kirkwood et al., 2002a).

Figure 5 shows the ratio of lidar backscatter to neutral density, as measured by the falling spheres, normalised so that the ratio is 1 (on average) between 50 and $60 \mathrm{~km}$ altitude. There is no evidence of any enhancement in the lidar backscatter (ratio $>1$ ) which might be expected from aerosol particle layers associated with the PMWE between $68-75 \mathrm{~km}$. Rather, the ratio is sometimes a little less than 1 , suggesting limitations in the measurement techniques/ analysis procedures. Either there are no aerosol particles or they are too small / too few to be detectable by the lidar. As discussed in (Stebel et al., 2004), the "dust" and "smoke" particles which are expected to be present as a result of meteor ablation can be expected to produce backscatter which is $10^{-4}$ less than that due to the atmospheric molecules. These particles are thought to have sizes of a few $\mathrm{nm}$ and number densities of a few thousand $\mathrm{cm}^{-3}$. Since the backscatter of light increases with the 6th power of the particle radius, however, a relatively small increase in size could lead to a substantial increase in backscatter. The rather short integration periods here, $1.5-2.5 \mathrm{~h}$, and the limitations of the technique, are not enough to reduce the uncertainty to a level where small backscatter enhancements below about $20 \%$ could be reliably detected at the heights where we observe PMWE. To produce such enhancements would require particle sizes of around $30 \mathrm{~nm}$, with number densities of a few thousand per $\mathrm{cm}^{-3}$, or a thousand-fold increase in number densities if particle sizes remain below $10 \mathrm{~nm}$. We note that previously published results, suggesting a possible 10\% lidar backscatter enhancement associated with PMWE, were based on a much longer integration time of almost $12 \mathrm{~h}$ (Stebel et al., 2004).

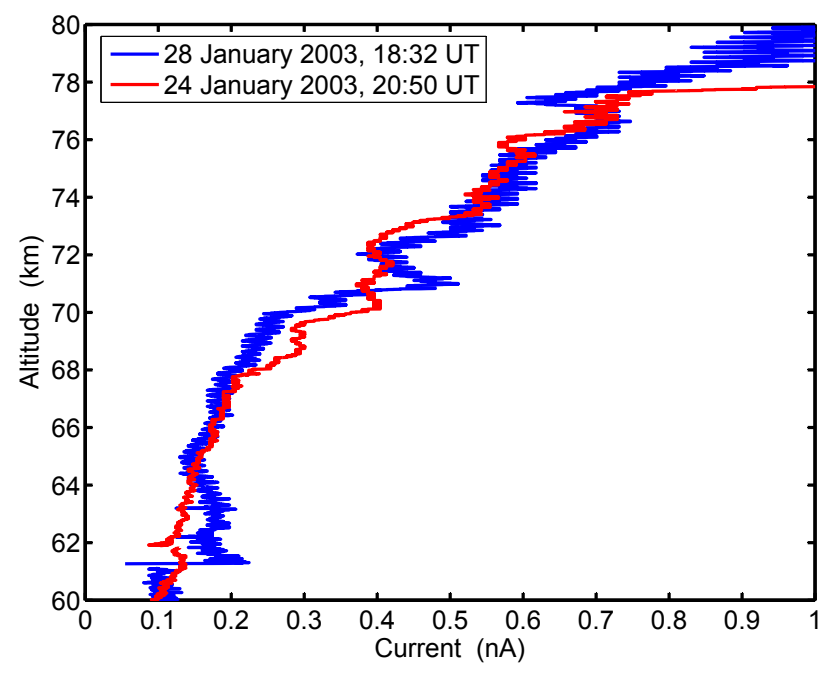

Fig. 6. Negative current measurements, indicative of relative negative charge densities, obtained by Langmuir probes on instrumented rocket payloads launched at 20:50 UT on 24 January 2003 and at 18:32 UT on 28 January 2003.

\section{Langmuir probe current measurements}

Two instrumented sounding rockets including Langmuir probes (Mitchell et al., 2003) were launched at 20:50 UT on 24 January 2003 and at 18:32 UT on 28 January 2003. Since PMWE were not the focus of the campaign, the timing of the instrumented payloads could not be chosen to coincide with PMWE. However, PMWE were detected earlier in the day on both occasions and it is possible that signatures of the structures corresponding to PMWE might still be present, although not sufficiently strongly to lead to detectable radar echoes. (In practice, PMWE below $75 \mathrm{~km}$ height are never been seen during night, presumably due to a lack of sufficient numbers of free electrons, Kirkwood et al., 2002a).

Figure 6 shows the probe current measurements, indicative of relative negative charge concentrations, which were obtained during rocket ascent for the two flights. An open Langmuir probe biased at $+5 \mathrm{~V}$ was used, so the collected current is due to both negative ions and any electrons that may be present. The general agreement between the two probe current profiles would suggest relatively comparable negative charge density levels, overall, during the two nighttime measurement periods. The finest scale fluctuations which are particularly pronounced for the data of 28 January are due to the spin-induced current modulation, while the sharp step at $61 \mathrm{~km}$ altitude on 28 January is likely an artefact of payload separation. The remaining variations, seen over most of the altitude region, appear to be evidence for vertical structure. For example, there are sharp ledges at about $69 \mathrm{~km}$ and $71 \mathrm{~km}$ and "bite-outs" close to 76 and $78 \mathrm{~km}$ on 24 and 28 January, respectively. 
The amount of variation in the profiles in Fig. 6 is not very large compared to the bite-outs seen in the vicinity of the summer mesopause region. However, it does provide evidence of small-scale structure in negative charge density, in the height region where PMWE are generally seen. It has been shown earlier (Kirkwood et al, 2002a), that PMWE are seen by the ESRAD radar only in conditions where electrons, rather than negative ions, are the negative charge carriers this corresponds to sunlit conditions. The profiles in Fig. 5 are all taken in night-time conditions where negative ions are likely to dominate below about $75 \mathrm{~km}$ altitude. The structures in charge density in Fig. 5 must have some underlying cause in the background atmosphere, such as a layer of aerosol particles or a layer where some minor constituent which is important for the ion chemistry (e.g. atomic oxygen) is enhanced or depleted. Such an underlying layer could be expected to cause structure in electron density during daylight conditions, but the effect cannot be estimated quantitatively without knowing the nature of the underlying layer.

There is no signature in the blunt probe data that would indicate the presence of charged aerosols. However, aerosols can sublime as they pass through the shock front so that small particles may never reach the instrument. The size limit is estimated to be about $7 \mathrm{~nm}$ at $84 \mathrm{~km}$, and probably higher at $70 \mathrm{~km}$. So the probe measurements cannot exclude the possibility of smaller particles.

\section{Conclusions}

Measurements made at Esrange during the MaCWAVE sounding-rocket campaign in January 2003 have been used to test whether layers of enhanced radar echo in the winter mesosphere (PMWE) are likely to be caused by turbulence or by charged aerosol.

Close to simultaneous, co-located measurements of atmospheric static stability and wind shear from the MaCWAVE falling spheres, and PMWE from the ESRAD radar have not provided any evidence of background conditions favouring turbulence associated with most PMWE. The majority of PMWE were seen in conditions that would not be expected to be associated with turbulence, at least on the vertical scale resolved by falling spheres (about a kilometre or more). Observed PMWE volume reflectivities are also found to be too high to be explained on the basis of previously published theory relating turbulence to radar echoes (Hocking, 1985) and published measurements of maximum turbulent intensity (Lübken et al., 1993; Lübken, 1997), unless some other process in addition to the turbulence creates small-scale gradients in electron density. A preliminary comparison of fallingsphere densities with lidar backscatter shows no distinct signal of any contribution of aerosol particles to the lidar scatter. However, a contribution of less than 10-20\% would not be detectable in the data available. Night-time Langmuir probe measurements show charge density structures in the height region where PMWE are seen during daytime. These suggest that underlying layers of aerosol particles or other minor constituents in the background atmosphere may be present. No direct evidence of aerosol particle presence can be found in the blunt-probe measurements, however these measurements are insensitive to small aerosol particles.

In conclusion, the action of neutral turbulence alone does not appear to give a good explanation for PMWE. At the same time, the possible role of aerosol particles remains uncertain.

Acknowledgements. The authors thank W. Singer, R. Latteck and P. Hoffmann for helpful discussions on the calculation of volume reflectivity from radar measurements. ESRAD is a partly owned and operated by Swedish Space Corporation, Esrange. The U. Bonn lidar measurements were supported by DLR Raumfahrt, grant DLR FKZ 50 EE 0009. U. Blum is supported by the Marie-Curie IntraEuropean Fellowship program of the European Community (MINERWA, No 010333).

Topical Editor U.-P. Hoppe thanks two referees for their help in evaluating this paper.

\section{References}

Balsley, B. B., Ecklund, W. L., and Fritts, D. C.: VHF echoes from the high-latitude mesosphere and lower thermosphere: observations and interpretations, J. Atmos. Sci., 40, 2451-2466, 1983.

Ecklund, W. L. and Balsley, B. B.: Long-term observations of the Arctic mesosphere with the MST radar at Poker Flat, Alaska, J. Geophys. Res., 86, 7775-7780, 1981.

Belova, E., Kirkwood, S., Ekeberg, J., Osepian, A., Häggström, I., Nilsson, H., and Rietveld, M.: The dynamical background of polar mesosphere winter echoes from simultaneous EISCAT and ESRAD observations, Ann. Geophys., 23, 1239-1247, 2005.

Blum, U. and Fricke, K. H.: The Bonn University at the Esrange: Technical description and capabilities for atmospheric research, Ann. Geophys., 23, 1645-1658, 2005.

Cho, J. Y. N. and Kelley, M. C.: Polar mesosphere summer radar echoes: Observations and current theories, Rev. Geophys., 31 , 243-265, 1993.

Cho, J. and Röttger, J.: An updated review of polar mesosphere summer echoes: Observations, theory, and their relationship to noctilucent clouds and subvisible aerosols, J. Geophys. Res., 102, 2001-2020, 1997.

Czechowsky, P., Reid, I. M., Rüster, R., and Schmidt, G.: VHF radar echoes observed in the summer and winter polar mesosphere over Andøya, Norway, J. Geophys. Res., 94, 5199-5217, 1989.

Friedrich, M., Harrich, M., Torkar, K. M., and Kirkwood, S.: The disturbed auroral ionosphere based on EISCAT and rocket data, Adv. Space Res., 33, 949-955, 2004.

Fritts, D. C., Bizon, C., Werne, J. A., and Meyer, C. K.: Layering accompanying turbulence generation due to shear instability and gravity-wave breaking, J. Geophys. Res., 108, 8452, do1:10.1029/2002JD002406, 2003.

Hocking, W. K.: Measurement of turbulent energy dissipation rates in the middle atmosphere by radar techniques: A review, Radio Sci., 20 , 1403-1422, 1985. 
Howard, L.: A note on the paper by John W. Miles, J. Fluid Mech., 10, 509-512, 1961.

Kelley, M. C., Farley, D. T., and Röttger, J.: The effect of cluster ions on anomalous VHF backscatter from the summer polar mesosphere, Geophys. Res. Lett., 14, 1031-1034, 1987.

Kennel C. F. and Petschek H. E.: Limit of stably trapped particle fluxes, J. Geophys. Res., 71, 1, 1-28, 1966.

Kirkwood, S. and Osepian, A.: Pitch angle diffusion coefficients and precipitating electron fluxes inferred from EISCAT radar measurements at auroral latitudes, J. Geophys. Res., 106, 55655578, 2001a.

Kirkwood, S. and Osepian, A.: Quantitative description of electron precipitation during auroral absorbtion events in the morning / noon local-time sector, J. Atmos. Sol. Terr. Phys., 63, 19071922, 2001b.

Kirkwood, S., Barabash, V., Belova, E., Nilsson, H., Rao, T. N., Stebel, K., Osepian, A., and Chilson, P. B.: Polar mesosphere winter echoes during solar proton events, Advances in Polar Upper Atmosphere Research 16, 111-125, 2002a.

Kirkwood, S., Barabash, V., Belova, E., Nilsson, H., Rao, T. N., Stebel, K., Blum, U., Fricke, K.-H., Osepian, A., and Chilson, P. B.: Polar Mesosphere Winter Echoes - by ESRAD, EISCAT and lidar, Memoirs of the British Astronomical Association, 45, paper 07, 2002b.

Lyons, L. R. and Williams, D. J.: Quantitative aspects of magnetospheric physics, D. Reidel, Dodrecht, Holland 1984.

Lyons, L. R., Thorne, R. M., and Kennel, F.: Electron pitch-angle diffusion driven by oblique whistler-mode turbulence, J. Plasma Phys., 6, 589-605, 1971.

Lyons, L. R., Thorne, R. M., and Kennel, F.: Pitch-angle diffusion of radiation-belt electrons within the plasmasphere, J. Geophys. Res., 77, 3455-3474, 1972.
Lübken, F.-J.: Seasonal variation of turbulent energy dissipation rates at high latitudes as determined by in situ measurements of neutral density fluctuations, J. Geophys. Res., 102, $13441-$ 13456, 1997.

Lübken, F.-J., Hillert, W., Lehmacher, G., and von Zahn, U.: Experiments revealing small impact of turbulence on the energy budget of the mesosphere and lower thermosphere, J. Geophys. Res., 98, 20369-20 384, 1993.

Maeda, K., Alvarez, H., Aparici, J., May, J., and Reich, P.: A 45$\mathrm{MHz}$ continuum survey of the northern hemisphere, Astron. Astrophys. Suppl. Ser., 140, 145-154, 1999.

Miles, J. W.: On the stability of heterogeneous shear flows, J. Fluid Mech., 10, 496-508, 1961.

Mitchell, J. D., Croskey, C. L., Goldberg, R. A., and Friedrich, M.: Charged particles in the polar mesopause region: Probe measurements from the MaCWAVE and DROPPS programs, Proc. 15th ESA Symposium on European Rocket and Balloon Programmes and Related Research, ESA-SP-530, 351-356, 2003.

Rapp, M. and Lübken, F.-J.: Polar mesosphere summer echoes (PMSE): Review of observations and current understanding, Atmos. Chem. Phys., 4, 2601-2633, 2004.

Røyrvik, O. and Smith, L. G.: Comparison of mesospheric VHF radar echoes and rocket probe electron concentration measurements, J. Geophys. Res., 89, 9014-9022, 1984.

Schmidlin, F. J., Lee, H. S., and Michel, W.: The inflatable sphere: A technique for the accurate measurement of middle atmosphere temperatures, J. Geophys. Res., 96 (D12), 22 673-22 682, 1991.

Stebel, K., Blum, U., Fricke, K.-H., Kirkwood, S., Mitchell, N. J. and Osepian, A.: Joint radar/lidar observations of possible aerosol layers in the winter mesosphere, J. Atmos. Sol. Terr. Phys., 66(11), 957-970, 2004. 